\title{
Condicionantes solares como princípio orientador da forma urbana: estudo de caso contextualizado no Distrito Federal
}

\author{
Solar constraints as a guiding principle for urban form: a \\ case study applied in the context of the Distrito Federal \\ (Brazil)
}

\section{Márcia Bocacio Birck Claudia Naves David Amorim}

\section{Resumo}

A forma urbana interfere no acesso dos edifícios à energia solar, o que influencia os níveis de radiação (irradiância), iluminação natural (iluminância) e potencial de produção energética, sendo necessário, portanto, considerar o aproveitamento da energia solar no desenho urbano. O estudo objetiva otimizar formas urbanas para o aproveitamento da energia solar em edifícios, considerando-se maximizar irradiância na cobertura e, ao contrário, minimizar irradiância e obter nível satisfatório de iluminância nas fachadas. Aplica-se à Região Administrativa do Gama (Distrito Federal), submetida à Lei de Uso e Ocupação do Solo (Luos). O método proposto é uma simplificação de Martins, Adolphe e Bastos (2014) e inclui a classificação de formas urbanas no ArcGIS; a definição e o cálculo do desempenho solar de 67 cenários, com DIVA e Grasshopper; e análises de iluminância e irradiância com vistas aotimizar formas urbanas. Os resultados mostram dificuldade em atingir níveis satisfatórios de iluminância em lotes pequenos, próximos e com alta taxa de ocupação. Obtiveram-se sete formas urbanas otimizadas, o que evidencia a necessidade de revisão dos parâmetros da Luos. Conclui-se sobre a relevância do desenho dos lotes (tamanho, afastamentos, orientação) e sua integração com os parâmetros de ocupação (taxa de ocupação e número de pavimentos).Ométodo utilizado demonstrou-se viável para otimizar formas urbanas quanto à energia solar e à iluminação natural,podendo ser replicado em outras condições.

Palavras-chave:Forma urbana. Desenho urbano. Energia solar. Iluminação natural.

\begin{abstract}
The urban form influences buildings' access to the sun, interfering in the levels of radiation (irradiance), daylight (illuminance) and energy production potential. Hence, one must consider the proper use of solar energy in the design of the urban form. This study aims to optimize urban forms based on the use of solar energy in buildings, considering the maximisation of irradiance on the roofs, and at the same time, the minimisation of irradiance and reception of a satisfactory level of illumination on façades. The study was applied in the Administrative Region of Gama (Distrito Federal, Brazil), subject to the Land Use and Occupancy Laws (LUOS). The method is a simplification of Martins, Adolphe and Bastos (2014) and includes the classification of the urban fabric, using ArcGIS; the calculation of

the solar performance for 67 scenarios, using both DIVA and Grasshopper

software; and an analysis, with irradiance and illuminance criteria, to define optimised urban forms. The results show that it is difficult to achieve satisfactory levels of illuminance on façades in lots that are small, close together and with high occupancy rates. Seven optimised forms were obtained, highlighting the need to review the LUOS parameters. The study concludes that the design of lots (size, spacing, orientation) and their integration with occupancy parameters (occupancy rate and number of floors) is highly relevant in urban planning. The method is feasible and can be replicated in different conditions.

Keywords: Urban form. Urban planning. Solar energy. Daylighting.
\end{abstract}

${ }^{1}$ Márcia Bocacio Birck Universidade de Brasília Brasília - DF - Brasil

${ }^{2}$ Cláudia Naves David Amorim ${ }^{2}$ Universidade de Brasília Brasília - DF - Brasil

Recebido em 12/05/19 Aceito em 08/08/19 


\section{Introdução}

A forma urbana interfere no acesso dos edifícios à energia solar, o que influencia seus níveis de radiação (irradiância) e de iluminação natural (iluminância), e seu potencial de produção energética. Em climas quentes, a irradiância recebida associa-se ao aumento da carga térmica no interior das edificações e ao aumento da possibilidade de utilização do recurso solar para produção energética fotovoltaica, enquanto a iluminância se associa ao aumento da disponibilidade de iluminação natural (COLOMBERT, 2008; TREGENZA; LOE, 2015).

$\mathrm{O}$ acesso dos edifícios à energia solar, no contexto das formas urbanas, depende de fatores espaciais, como a altura dos edifícios, sua implantação e seus afastamentos, e de fatores temporais, influenciados pela implantação dos edifícios (GROSSO, 1998; RATTI; BAKER; STEEMERS, 2005). Áreas urbanas muito densas podem impossibilitar o uso da iluminação natural, o que aumenta o consumo energético das edificações. Além disso, a implantação dos edifícios é um fator fundamental para garantir a adequada produção energética por meio dos sistemas fotovoltaicos, já que um dos principais fatores que influenciam negativamente o desempenho desses sistemas é o sombreamento (MONTAVON, 2010; RATTI; BAKER; STEEMERS, 2005).

Tendo em vista que a forma urbana (configuração do grupo de edificações, dimensões dos edifícios e seus afastamentos) e as propriedades dos materiais utilizados afetam a incidência da radiação solar e a perda de calor na edificação, o planejamento urbano pode melhorar significativamente as condições dos ambientes externos e internos (LITTLEFAIR, 2001).

A fim de possibilitar melhor eficiência energética das construções, é necessária a concepção de formas urbanas que tenham como objetivo a diminuição do consumo de recursos energéticos, através de medidas e estratégias de adaptação que diminuam os impactos ambientais. Além disso, deve-se também incentivar a maior utilização de fontes de energia renováveis.

O Brasil possui condições climáticas favoráveis à utilização dos sistemas fotovoltaicos, com alta disponibilidade e uniformidade de radiação solar. Entretanto, a participação dessa fonte renovável ainda é pouco expressiva; corresponde a $0,5 \%$ da matriz energética. Com pequena, mas crescente capacidade instalada, o Brasil tem buscado inserir a geração fotovoltaica na matriz brasileira (CRONEMBERGER, 2015; MINISTÉRIO...; EMPRESA..., 2019).

O Distrito Federal (DF) tem grande potencial de implantação de edifícios de baixo consumo energético e com possibilidade de produção de energia solar fotovoltaica por se localizar em uma região de clima favorável para a adoção de estratégias passivas de condicionamento térmico e de iluminação natural e com potencial para produção solar fotovoltaica (DOMINGOS et al., 2014; LAMBERTS; DUTRA; PEREIRA, 2014; MINISTÉRIO...; EMPRESA..., 2014).

No entanto, o aproveitamento da energia solar nas envoltórias dos edifícios pode influenciar a construção de formas urbanas dispersas, aumentando-se a carga térmica recebida pela edificação. A forma urbana compacta, por outro lado, pode limitar a disponibilidade de iluminação natural e de radiação solar a ser utilizada como fonte de energia renovável (MARTINS; ADOLPHE; BASTOS, 2014).

Sendo assim, pergunta-se quais seriam as melhores formas urbanas em relação ao aproveitamento da energia solar nas envoltórias dos edifícios levando-se em consideração a disponibilidade de iluminação natural, o controle térmico e a produção de energia solar fotovoltaica em uma região de clima tropical de altitude, no contexto do DF.

A pesquisa objetiva então definir formas urbanas adequadas ao contexto climático que permitam a utilização da iluminação natural e a produção de energia solar fotovoltaica com o menor ganho possível de carga térmica. Dessa maneira, determinaram-se formas urbanas otimizadas, levando em consideração três estratégias: maximização dos níveis de irradiância na cobertura (objetivando-se produzir energia através de painéis fotovoltaicos); minimização dos níveis de irradiância nas fachadas (objetivando-se diminuir a carga térmica nos ambientes); e recebimento de um nível satisfatório de iluminância nas fachadas (garantindo-se adequada disponibilidade de iluminação natural nos ambientes).

O estudo aplicou-se à Região Administrativa do Gama, polo de concentração populacional da região sudoeste do DF, onde vem ocorrendo um processo acentuado de verticalização. A forma urbana do Gama se subordina, desde janeiro de 2019, à Lei de Uso e Ocupação do Solo (Luos), instrumento de ordenamento territorial que regula o tipo de utilização dos lotes e indica parâmetros de ocupação. Busca-se avaliar o

592 Birck, M. B.; Amorim, C. N. D. 
desempenho solar de diferentes formas urbanas, identificando as que melhor aproveitam o recurso solar, de acordo com as condicionantes propostas.

\section{Método}

O método do artigo baseia-se no método de Martins, Adolphe e Bastos (2014), que investiga o potencial de aproveitamento da energia solar como recurso renovável para a produção de eletricidade, de demanda de energia devido aos ganhos de calor nos edifícios e dedisponibilidade de luz natural nos edifícios, calculandose as formas urbanas otimizadas, de acordo com critérios definidos.

O método divide-se em três etapas principais:

(a) etapa 1: Classificação das classes tipomorfológicas urbanas de referência;

(b) etapa 2: Cálculo do desempenho solar nas classes tipomorfológicas urbanas de referência; e

(c) etapa 3: Otimização da forma urbana, considerando critérios preestabelecidos, e, no caso da irradiância, o método de aglutinação por convergência de resultados, ambos detalhados adiante.

A Figura 1 resume o método.

Descrevem-se a seguir em detalhes as etapas.

\section{Etapa 1: classificação morfológica}

\section{Etapa 1.1: definição do objeto de estudo e dos parâmetros a serem estudados}

Definiram-se critérios para a escolha do objeto de estudo e delimitou-se a área do objeto de estudo, sujeita à Luos. Tendo em vista que se avaliou a forma urbana proposta pela Luos, utilizaram-se seus parâmetros de ocupação neste estudo.

\section{Etapa 1.2: simulação dos potenciais construtivos}

Após a escolha do objeto de estudo, configurou-se a forma urbana, considerando-se o máximo potencial construtivo permitido pela Luos. Utilizou-se o programa computacional CityZoom 2.0 (TURKIENICZ; GONÇALVES; GRAZZIOTIN, 2008)para definição da forma edilícia e urbana a ser estudada. O programa gera automaticamente a forma dos edifícios através da definição dos parâmetros de ocupação, permitindo que a forma dos edifícios seja maximizada por meio da altura ou pela taxa de ocupação. Estipulou-se que a forma dos edifícios fosse maximizada pelo número de pavimentos.

Figura 1 - Etapas do método utilizado

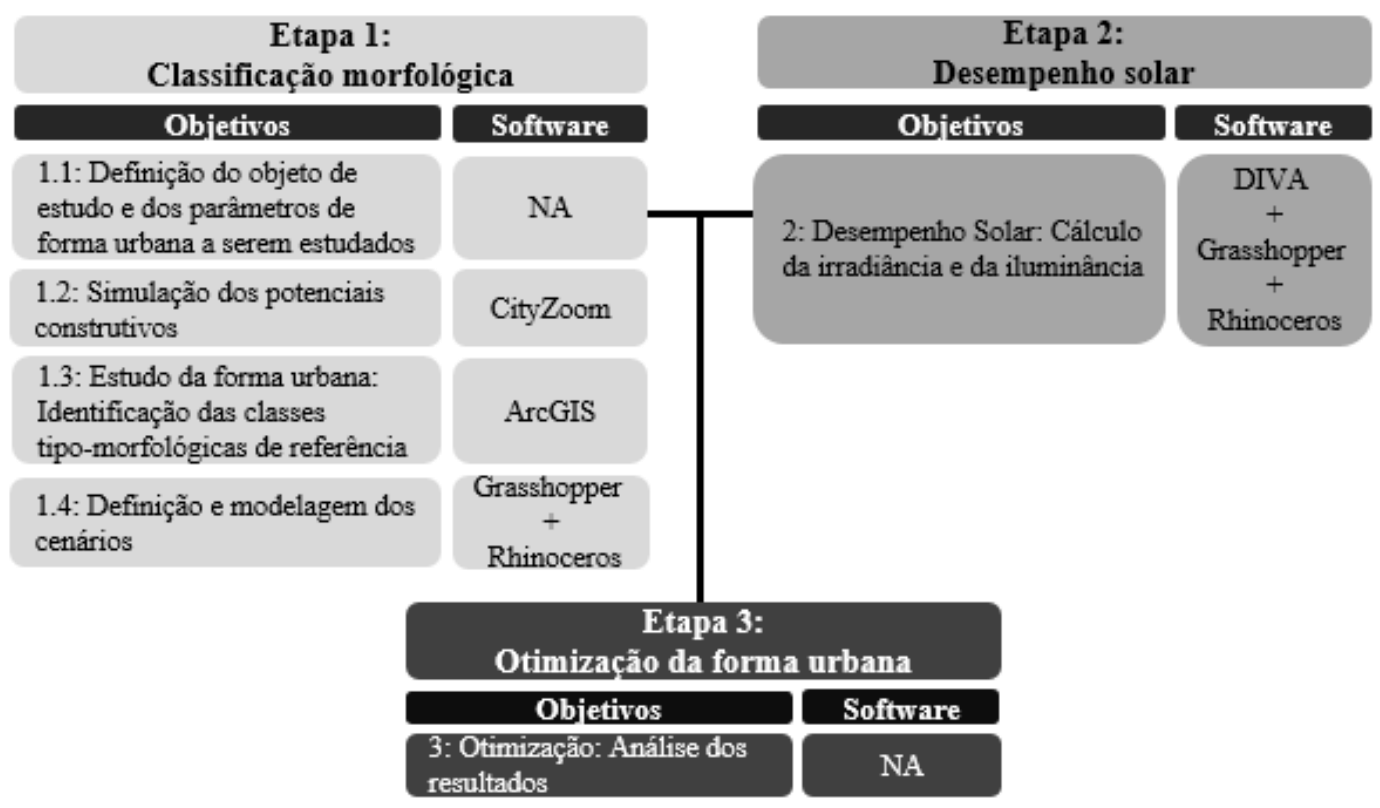

Nota: NA: Não se aplica. 


\section{Etapa 1.3: estudo da forma urbana: identificação das classes tipo morfológicas}

O ambiente urbano, ao ser composto de diferentes unidades espaciais, caracteriza-se por não apresentar uma superfície única representativa do tecido. Entretanto, é possível classificá-lo em unidades representativas da superfície urbana, denominadas classes tipo morfológicas urbanas de referência, de acordo com a repetição e a combinação de suas formas básicas. Como exemplo desse tipo de aplicação tem-se o artigo de Martins, Adolphe e Bastos (2014), que classifica a forma urbana de uma cidade de clima tropical, Maceió, AL, em cinco classes tipo morfológicas de referência.

Essa etapa abarca a identificação e a distribuição das classes tipo morfológicas urbanas de referência (as formas urbanas mais representativas da malha urbana do objeto de estudo) e a produção de plantas temáticas relativas aos parâmetros selecionados.

A partir de um Sistema de Informação Geográfica (SIG) - ArcGIS, inseriu-se a forma urbana resultante da Etapa 1.2 em uma malha de análise, em que foram calculados, para cada unidade dessa malha, os parâmetros que melhor caracterizam a forma urbana, a saber:

(d) altura média ponderada: razão entre a soma das alturas dos edifícios ponderadas por suas áreas construídas no solo da malha e a área total construída;

(e) coeficiente de forma: razão entre a área de envoltória dos edifícios e seu volume elevado à potência de $2 / 3$;

(f) contiguidade: razão entre a área das paredes geminadas e a área total da envoltória;

(g) densidade construída: razão entre a soma das áreas construídas e a área total da malha; e

(h) rugosidade: razão entre a soma das áreas construídas dos edifícios ponderadas por suas alturas e a área total construída e não construída (MARTINS; ADOLPHE; BASTOS, 2014; SALAT, 2011).

Utilizou-se a escala espacial de $250 \mathrm{~m}$ por $250 \mathrm{~m}$, correspondente a uma quadra do Gama.

Com base nos cálculos dos parâmetros, as classes tipo morfológicas foram definidas estatisticamente, de acordo com a predominância de suas características. Utilizou-se um método estatístico de agrupamento de dados (clustering analysis), que agrupa automaticamente, em grupos ou classes, um conjunto de dados estatisticamente semelhantes entre si. Essa classificação, por sua vez, foi inserida na tabela de atributos no ArcGIS, na qual para cada célula da malha foi atribuída sua classe correspondente. Dessa maneira, pôde-se ilustrar cartograficamente a distribuição das classes tipo morfológicas na malha urbana e também pôde-se produzir plantas temáticas com os parâmetros morfológicos calculados.

\section{Etapa 1.4: definição e modelagem dos cenários}

Para cada classe calculada, escolheu-se uma quadra representativa a ser estudada, objeto de modelagem dos cenários.

Definiram-se os cenários a serem estudados com base nos parâmetros de ocupação da Luos (coeficiente de aproveitamento básico e máximo, taxa de ocupação, taxa de permeabilidade, número de pavimentos, altura máxima e afastamentos mínimos), obedecendo aos limites estabelecidos para cada uso do solo.

Examinaram-se as duas principais situações de afastamento, definidas como as mais observadas nas quadras representativas de cada classe. Para as Classes 1 e 2, caracterizaram-se as duas principais situações: uma considerando que haveria afastamentos laterais, e outra que não haveria afastamentos laterais. Em ambas as situações, os edifícios se localizariam no centro do lote. Para a Classe 3, as duas principais situações são: uma considerando todos os afastamentos de maneira proporcional, na qual os edifícios se localizariam no centro do lote; e outra localizando os edifícios no limite do fundo do lote, respeitando-se o afastamento de fundo de 3,00 m. Além disso, estabeleceu-se que alguns cenários utilizariam o máximo potencial construtivo, ou seja, o coeficiente de aproveitamento máximo. Entre esses cenários, alguns teriam sua forma maximizada pela taxa de ocupação, e outros, maximizada pelo número de pavimentos. A partir desses cenários, criaram-se cenários intermediários.

Tais cenários foram modelados utilizando-se o Grasshopper, ferramenta de modelagem algorítmica executada dentro do programa Rhinoceros. Montou-se um padrão de cálculo no Grasshopper para realizar a modelagem generativa a partir dos parâmetros de taxa de ocupação, pé esquerdo, número de pavimentos e presença ou ausência de afastamentos, conforme ilustra a Figura 2. Esse padrão foi utilizado para o desenvolvimento de todas as modelagens. 
Figura 2 - Representação do padrão de cálculo estruturado no Grasshopper

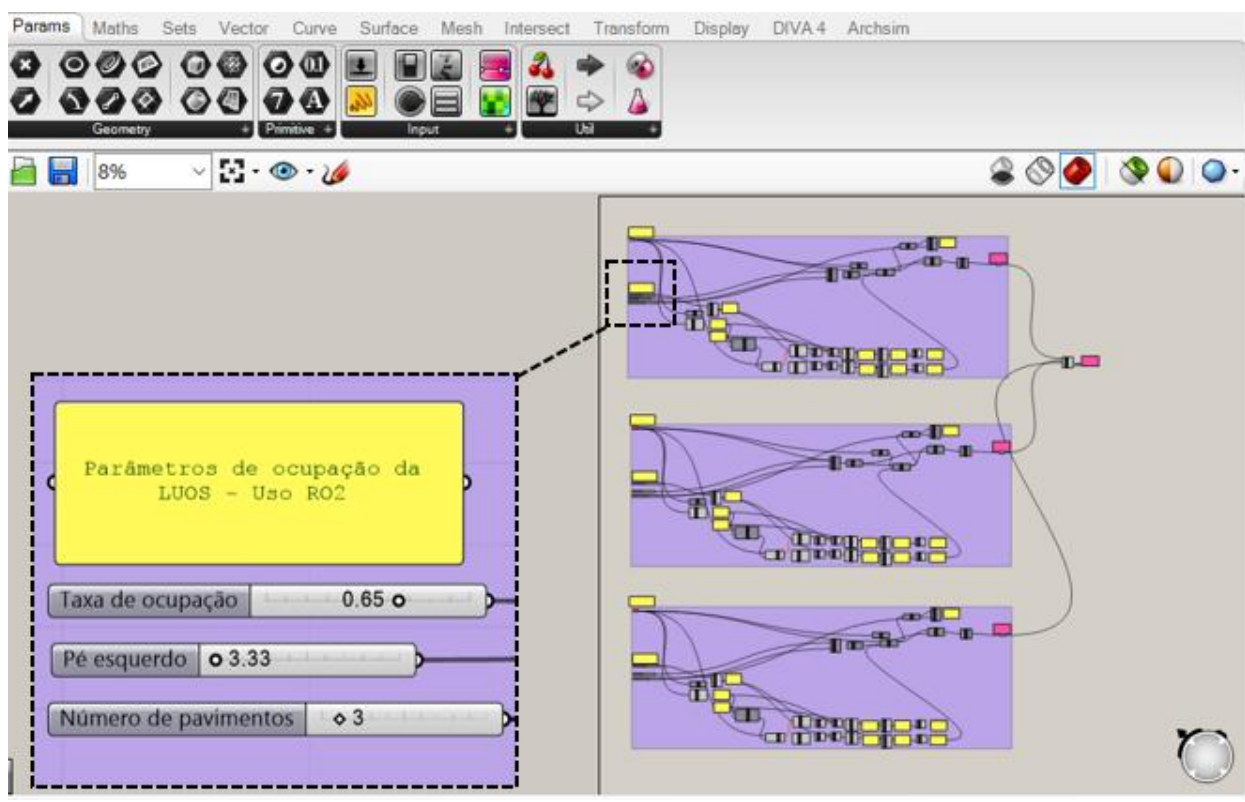

\section{Etapa 2: desempenho solar: cálculo da irradiância e da iluminância}

Calculou-se o desempenho solar de cada cenário definido na Etapa 1.4, utilizando-se o programa Rhinoceroscom os plugins DIVA e Grasshopper. No DIVA, especificaram-se os materiais a serem utilizados e calcularam-se a irradiância anual incidente nas fachadas e nas coberturas e a iluminância média anual incidente nas fachadas. Os dados de saída foram lidos no Excel, e os resultados obtidos foram comparados entre si. Consideraram-se, para todos os cenários, as mesmas configurações de materiais, de acordo com as refletâncias predominantes existentes no objeto de estudo.

Para o cálculo da irradiância e iluminância, o DIVA requisita a criação de uma malha de análise e a escolha da localização. Utilizou-se o arquivo climático de Brasília (LABORATÓRIO..., 2016) em formato .epw, e configurou-se uma malha de análise de um por um metro. $\mathrm{O}$ resultado numérico final de irradiância se refere à irradiância anual total calculada para cada unidade da malha de análise dividida pela área analisada. $\mathrm{O}$ resultado de iluminância apresentado corresponde à média das iluminâncias calculada em cada unidade da malha de análise, das 8 h00 às $16 \mathrm{~h} 00$.

\section{Etapa 3: otimização: análise dos resultados}

A análise dos resultados compreendeu três etapas: análise das iluminâncias (eliminatória), análise das irradiâncias (classificatória) e análise de potencial energético (complementar). A otimização consiste em encontrar os cenários com melhor desempenho em facedos critérios definidos.

$\mathrm{Na}$ análise das iluminâncias nas fachadas, verificou-se se os edifícios de determinado cenário recebem um nível satisfatório de iluminância nas fachadas. Para tal, estabeleceu-se como critério o limite mínimo de iluminância a ser recebido em cada orientação da fachada, adotando-se o método proposto por Moraes e Pereira (2011). Tal método considera um valor anual mediano de iluminância difusa externa para obter o valor mínimo adequado de fator de luz diurna (FLD) e, por consequência, de iluminância interna. Para isso, analisam-se histogramas de frequência acumulada de iluminância difusa externa para a localidade em estudo, considerando uma frequência de 50\% durante o ano. Em seguida, definiu-se a iluminância interna desejada e determinou-se o FLD. Os dados de iluminâncias externas para Brasília foram obtidos de Scarazzato (1995) utilizando-se as iluminâncias na condição de céu predominante parcialmente encoberto durante o ano. Considerou-se como iluminância interna mínima a ser obtida o valor de 100 lux (NABIL; MARDALJEVIC, 2006).

A Tabela 1 apresenta os limites de iluminância externa por orientação de fachada para que o nível de iluminância interna resultante seja considerado satisfatório. Se as fachadas receberam níveis menores do que o indicado, os cenários em questão foram desclassificados. Nesse sentido, a análise das iluminâncias tem caráter eliminatório. 
Tabela 1 - Limite mínimo de iluminância externa (lux) por orientação de fachada

\begin{tabular}{|c|c|c|c|c|c|c|c|c|}
\hline & \multicolumn{8}{|c|}{ Orientação da fachada } \\
\hline & Norte & Nordeste & Leste & Sudeste & Sul & Sudoeste & Oeste & Noroeste \\
\hline $\begin{array}{l}\text { Limite } \\
\text { mínimo de } \\
\text { iluminância } \\
\text { externa } \\
\text { (lux) }\end{array}$ & 983 & 8.233 & 7.600 & 7.167 & 6.800 & 6.733 & 7.467 & 8.967 \\
\hline
\end{tabular}

A análise das irradiâncias é uma etapa classificatória, na qual se consideraram os melhores cenários como aqueles que receberam maior irradiância nas coberturas e menor irradiância nas fachadas. Tendo em vista que essa análise abrange dois objetivos contraditórios, é necessária a convergência dos resultados para se chegar a uma conclusão. Sendo assim, seguiu-se o método de aglutinação por meio do desvio padrão percentual proposto por Salomon e Shimizu (2006), no qual se determina o valor ótimo para cada objetivo, subtrai-se desse valor o valor analisado e divide-se o resultado pelo valor ótimo. O resultado encontrado é a soma dos desvios percentuais. Quanto menor for esse número, melhor é considerado o resultado.

A análise de potencial energético tem como objetivo averiguar se a produção energética do cenário analisado seria superior a sua demanda energética. Tal etapa se aplicou apenas aos cenários que passaram na análise das iluminâncias e ofereceu uma resposta complementar à análise das irradiâncias. O cálculo da demanda e da produção energética se deu de maneira simplificada, baseando-se em um estudo da Empresa de Pesquisa Energética (MINISTÉRIO...; EMPRESA..., 2014), que relaciona a produção energética à irradiância recebida pela cobertura e à área de cobertura disponível para a implantação do sistema. Levou-se em consideração que a área de cobertura disponível seria $75 \%$ da área total de cobertura (KANTERS; HORVAT, 2012) e que o fator de conversão da energia solar incidente em energia elétrica seria de $12 \%$ (MINISTÉRIO...; EMPRESA..., 2014).

Para a estimativa da demanda energética, separaram-se as edificações analisadas de determinada quadra entre uso residencial e não residencial. Multiplicou-se o padrão de consumo residencial ou não residencial, $\mathrm{em} \mathrm{kWh} / \mathrm{m}^{2}$.ano, pela metragem quadrada dos edifícios da quadra, conforme os usos definidos pela Luos (Tabela 2). Para os usos RE3 - Setor Central - Tipo B, RO1 (2) e RO2, utilizaram-se os valores relativos ao uso residencial. Para os usos CSIIR2 (1), CSIIR2 (2) e CSIIR2-Leste Industrial (1), utilizaram-se os valores relativos ao uso não residencial. O padrão de consumo residencial utilizado para Brasília foi de 29,91 $\mathrm{kWh} / \mathrm{m}^{2}$.ano (FEDRIGO; GHISI; LAMBERTS, 2009), e o padrão de consumo não residencial utilizado foi de $84,01 \mathrm{kWh} / \mathrm{m}^{2}$.ano, valor derivado da média de consumo energético de edifícios de escritórios em Brasília (COSTA; OLIVEIRA; AMORIM, 2017).

A partir do resultado dessas três etapas, concluíram-se quais seriam os cenários que melhor contemplaram as estratégias do processo de otimização e que, consequentemente, se mostraram como os cenários mais adequados ao contexto climático do objeto de estudo (tidos como os cenários otimizados).

\section{Objeto de estudo}

A Região Administrativa do Gama foi definida como objeto de estudo baseando-se nos seguintes critérios: é uma área com potencial de expansão urbana, inserida em clima tropical de altitude e sujeita à LUOS.

O DF apresenta uma taxa de crescimento populacional anual de aproximadamente $2,18 \%$, acima da média nacional, de 0,82\%, uma das maiores do país (INSTITUTO..., 2016). Observa-se o aumento da oferta de habitações em edifícios multifamiliares verticais nas regiões administrativas próximas ao Plano Piloto de Brasília. Em algumas dessas regiões, como no Gama, devido aos interesses imobiliários, as alturas de gabarito e o potencial construtivo foram modificados, levando à verticalização das construções (FREITAS, 2013).

\section{Caracterização territorial do Gama/DF}

O Gama (Região Administrativa II) localiza-se na região sudoeste do DF e situa-se a aproximadamente 30 km do Plano Piloto, conforme ilustra a Figura 3. 
A zona urbana do Gama insere-se em uma área com pouca possibilidade de crescimento horizontal devido a sua limitação espacial com as Zonas Rurais de Uso Controlado e a Macrozona de Proteção Integral (DIRETORIA...; CAMPANHIA..., 2015), como demonstra a Figura4.

A dinâmica urbana incentivou o processo de verticalização dessa área, também prevista pela Lei de Uso e Ocupação do Solo (Luos).

\section{Lei de uso e ocupação do solo}

No contexto do Distrito Federal, tem-se a Luos como instrumento de ordenamento territorial que regula o tipo de utilização para os lotes urbanos de 24 regiões administrativas do Distrito Federal, incluindo o Gama. A Luos determina o uso e os parâmetros de ocupação dos lotes, sendo composta da Tabela de Usos e Atividades da Luos e demapas de uso do solo por localidade urbana, entre outros (DISTRITO..., 2019). Para o artigo em questão, utilizaram-se os documentos Mapa de Zoneamento de Usos da Região Administrativa do Gama (SECRETARIA..., 2016a) e Tabela de Parâmetros de Ocupação do Solo da Região Administrativa do Gama (SECRETARIA..., 2016b) disponíveis em 2016.

O uso refere-se ao conjunto das atividades permitidas no interior do lote, sendo elas submetidas a critérios de exclusividade, obrigatoriedade e simultaneidade. As atividades classificam-se em residencial exclusivo (RE), residencial obrigatório (RO), comercial, prestação de serviços, institucional, industrial e residencial (CSIIR), entre outros.

A Luos determina para cada uso do solo os seguintes parâmetros de ocupação: coeficiente de aproveitamento, taxa de ocupação, taxa de permeabilidade, afastamentos e altura máxima e afastamentos mínimos, conforme demonstra a Tabela 2.

As situações testadas respeitam os limites estabelecidos para cada uso do solo. Para as Classes 1 e 2, não há afastamento lateral mínimo, ou seja, podem ser analisadas configurações sem e com afastamento lateral. Somente o uso RO2 tem afastamento frontal mínimo, de 1,50 m. Para a Classe 3, as duas principais situações são edifícios no centro do lote e no limite do fundo do lote. Em ambas as situações, os afastamentos laterais e de fundo são de $3,00 \mathrm{~m}$.

Figura 3 - Localização do Gama no DF

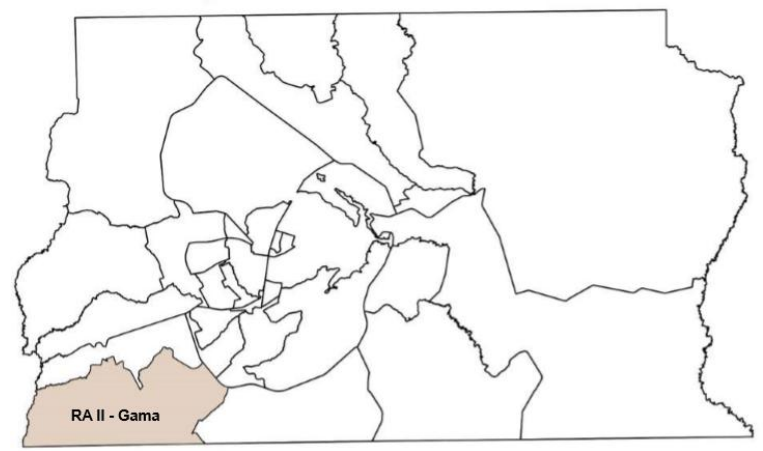

Fonte: Diretoria de Estudos Urbanos e Ambientais e Companhia de Planejamento do Distrito Federal(2015).

Figura 4 - Limites do Gama
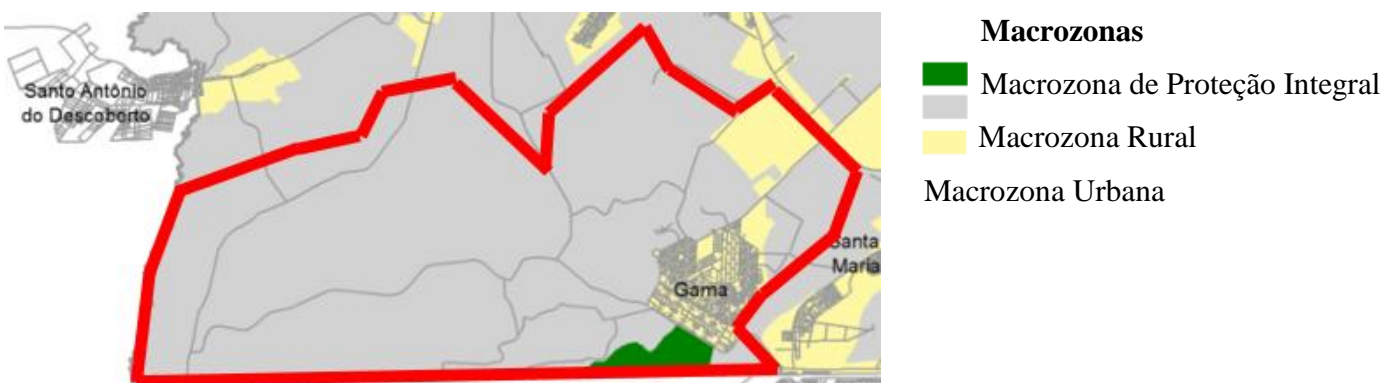

Fonte: Diretoria de Estudos Urbanos e Ambientais e Companhia de Planejamento do Distrito Federal (2015). 


\section{Resultados e discussões}

Nesta seção apresentam-se os resultados obtidos de acordo com as etapas descritas no método.

\section{Etapa 1: classificação morfológica}

\section{Etapa 1.3: estudo da forma urbana: identificação das classes tipo morfológicas}

O resultado viabilizou a produção de plantas temáticas, como a de altura média ponderada, ilustrada na Figura 5.

Tabela 2 - Parâmetros de ocupação da Luos utilizados

\begin{tabular}{l|l|c|c|c|c}
\hline \multicolumn{1}{c|}{ Uso } & \multicolumn{1}{|c|}{ Caracterização } & $\begin{array}{c}\text { Coeficiente } \\
\text { de aprov. } \\
\text { máximo }\end{array}$ & $\begin{array}{c}\text { Taxa de } \\
\text { ocupação } \\
\text { máxima }\end{array}$ & $\begin{array}{c}\mathbf{N}^{\circ} \text { de } \\
\text { pav. } \\
\text { máximo }\end{array}$ & $\begin{array}{c}\text { Afastamentos } \\
\text { mínimos }\end{array}$ \\
\hline $\begin{array}{l}\text { RE3 - Setor } \\
\text { Central -B }\end{array}$ & $\begin{array}{l}\text { Uso residencial unifamiliar } \\
\text { ou multifamiliar exclusivo }\end{array}$ & 9,00 & $100 \%$ & 9 & Sem restrições \\
\hline RO1 (2) & $\begin{array}{l}\text { Uso residencial } \\
\text { unifamiliar. Não } \\
\text { residenciais permitidas }\end{array}$ & 2,00 & $80 \%$ & 3 & Sem restrições \\
\hline RO2 & Idem RO1 & 2,00 & $80 \%$ & 3 & Frontais (1,50 m) \\
\hline CSIIR2 (1) & $\begin{array}{l}\text { Uso não residencial } \\
\text { obrigatório: comercial, } \\
\text { serviços, industrial/instit. }\end{array}$ & 4,00 & $100 \%$ & 3 & Sem restrições \\
\hline CSIIR2 (2) & Idem CSIIR2 & 4,00 & $100 \%$ & 4 & Sem restrições \\
\hline $\begin{array}{l}\text { CSIIR2 } \\
\text { Leste/Indus- } \\
\text { trial (1) }\end{array}$ & Idem CSIIR2 & 3,00 & $60 \%$ & 20 & $\begin{array}{l}\text { Laterais/fundo } \\
(3.00 \text { m) }\end{array}$ \\
\hline
\end{tabular}

Fonte: Secretaria de Estado de Gestão do Território e Habitação (2016).

Figura 5- Planta temática de altura média ponderada do Gama, elaborada com ArcGIS

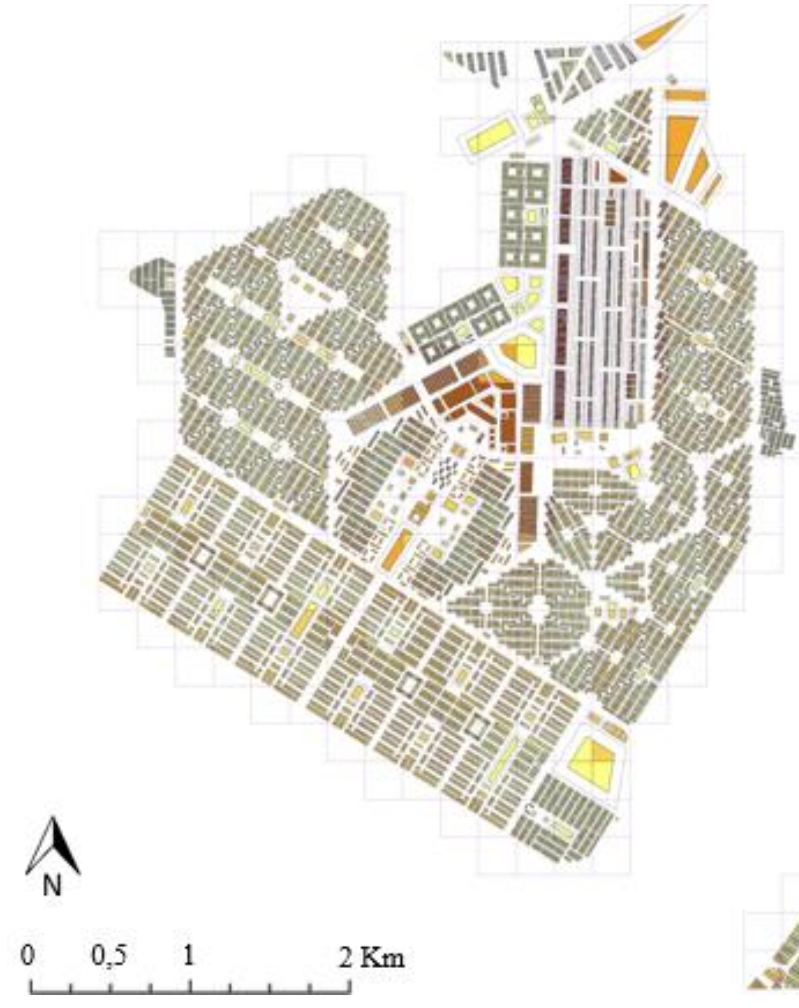

Legenda:

9,0-10,7 m

$10,8-13,8 \mathrm{~m}$

$13,9-22,2 \mathrm{~m}$

$22,3-42,3 \mathrm{~m}$

42,4-73,4 m

598 Birck, M. B.; Amorim, C. N. D. 
Há predominância de edifícios horizontais ${ }^{1}$ (com altura média de 12,72m), com rugosidade média de 4,59, densidade média de 3,46, coeficiente de forma médio de 3,31 e contiguidade média de 0,35. Esses parâmetros são os considerados por Martins, Adolphe e Bastos (2014) como os que melhor caracterizam a forma urbana.

O resultado também viabilizou a identificação e a distribuição das classes tipo morfológicas de referência. Realizou-se um agrupamento em três classes tipo morfológicas, conforme ilustram as Figuras 6 e 7 e conforme caracteriza a Tabela 3.

A Classe 1, ou classe horizontal contínua, representa $85 \%$ do tecido urbano do Gama. Caracteriza-se por ser predominantemente horizontal, com edificações contínuas (sem afastamentos laterais), com baixa densidade construída e pouca rugosidade. Os lotes da quadra representativa da Classe 1 são pequenos e adjacentes. Eles possuem taxa de ocupação de $80 \%$ e $100 \%$, e as edificações possuem três e quatro pavimentos, variando de acordo com o uso. Verificou-se que as diretrizes construtivas para a Classe 1 incentivam a horizontalidade da forma urbana, sendo permitidas edificações de até quatro pavimentos. A ausência dos afastamentos laterais estimula a construção de edifícios geminados.

Tabela 3 - Características morfológicas das três classes

\begin{tabular}{c|l|c|c|c|c|c}
\hline Classe & Nome & $\begin{array}{c}\text { Altura } \\
\text { ponderada } \\
\text { média (m) }\end{array}$ & $\begin{array}{c}\text { Coeficiente } \\
\text { de forma } \\
\text { médio }\end{array}$ & $\begin{array}{c}\text { Contigui- } \\
\text { dade média }\end{array}$ & $\begin{array}{c}\text { Densidade } \\
\text { construída } \\
\text { média }\end{array}$ & $\begin{array}{c}\text { Rugosidade } \\
\text { média }\end{array}$ \\
\hline 1 & Horizontal contínuo & 11,09 & 2,96 & 0,39 & 3,07 & 4,05 \\
2 & Horizontal rugoso & 14,49 & 5,07 & 0,16 & 3,62 & 6,48 \\
3 & Vertical denso & 56,92 & 6,45 & 0,06 & 15,37 & 13,36 \\
\hline
\end{tabular}

Figura 6 - Distribuição das três classes tipo morfológicas do Gama, no ArcGIS

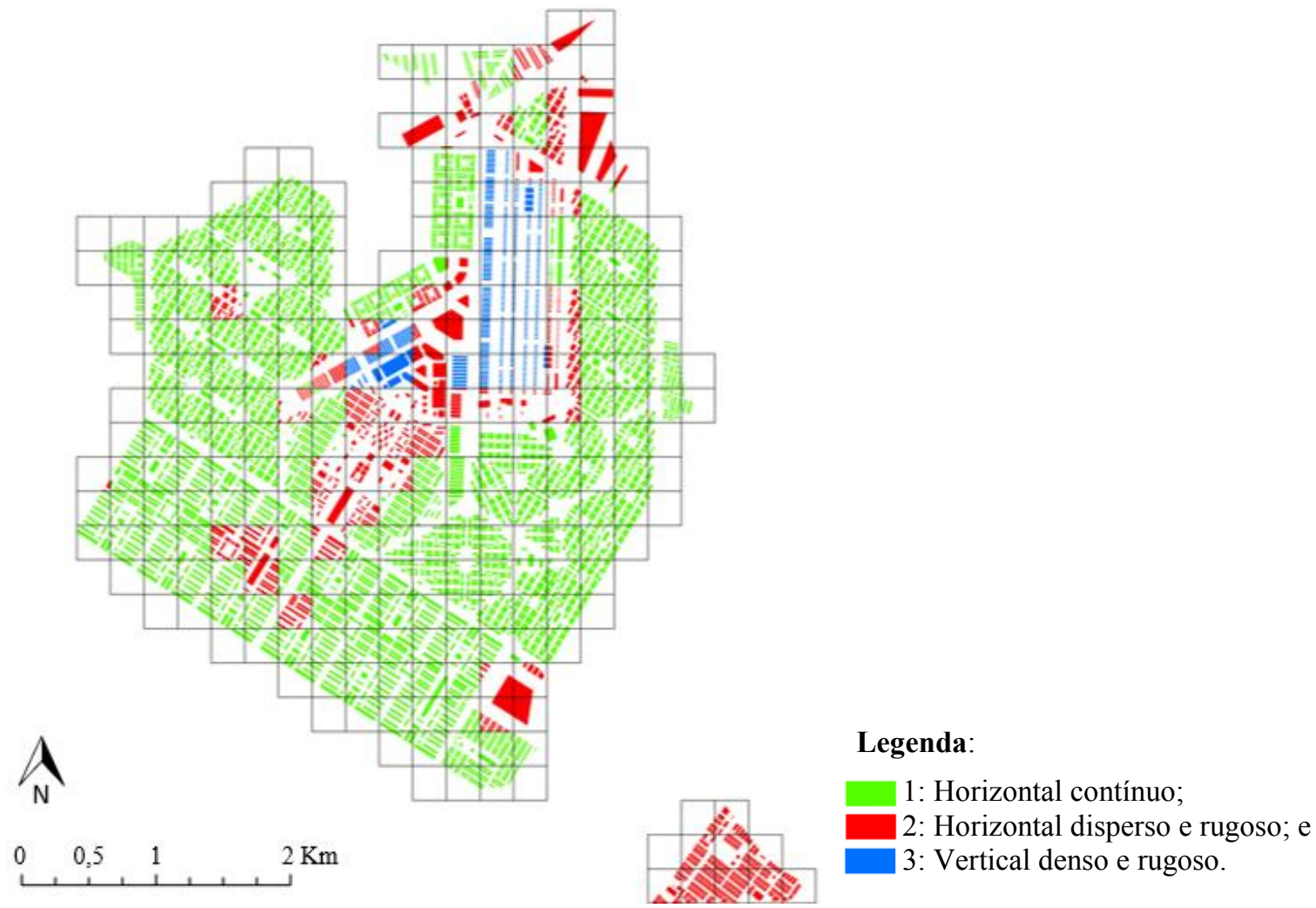

${ }^{1}$ Salat (2011) considera que uma malha urbana vertical tem altura igual a 35,8 m. Nesse sentido, considerou-se que as classes com altura superior a $35,8 \mathrm{~m}$ de altura seriam verticais, e as de altura inferior, horizontais. 
Figura 7 - Modelo 3D das três quadras representativas das classes, elaborado no Rhinoceros

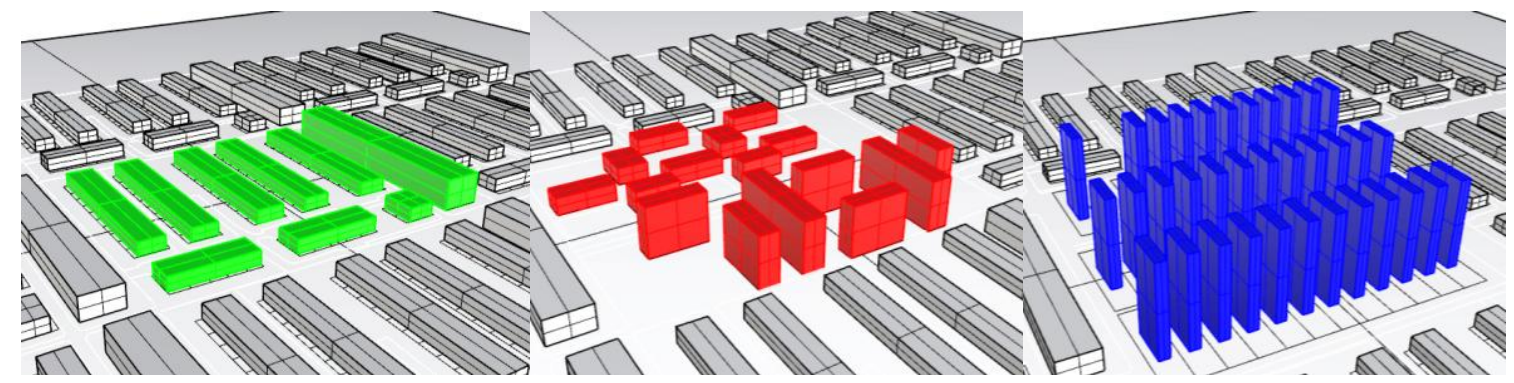

A Classe 2, ou classe horizontal rugosa, representa apenas 3\% do tecido urbano do Gama. Caracteriza-se por ser predominantemente horizontal, com edificações pouco contínuas e com baixa densidade construída, gerando uma forma urbana mais dispersa e mais rugosa que a Classe 1.A quadra representativa da Classe 2 é composta por lotes grandes, distantes um do outro, e por lotes pequenos e adjacentes. Os lotes possuem taxa de ocupação de $100 \%$, e as edificações possuem três, quatro e nove pavimentos, variando de acordo com o uso. A ausência dos afastamentos laterais em alguns lotes estimula a construção de edifícios geminados.

A Classe 3, ou classe vertical densa, representa $12 \%$ do tecido urbano do Gama. É predominantemente vertical, com edificações pouco contínuas, com grande densidade construída e bastante rugosa. Os lotes da quadra representativa da Classe 3 são grandes e adjacentes. Eles possuem taxa de ocupação de $15 \%$, e as edificações possuem vinte pavimentos. Verificou-se que as diretrizes construtivas para a Classe 3 incentivam a verticalidade da forma urbana, sendo permitidas edificações de até $73,40 \mathrm{~m}$ de altura. A maioria dos lotes possui afastamentos laterais e de fundo.

Avaliou-se e comparou-se o desempenho de um dos cenários de cada uma das três classes (cenário com coeficiente de aproveitamento máximo e maximizado pelo número de pavimentos). A Tabela 4 apresenta os resultados, verificando-se variação pouco significativa entre os resultados de irradiância anual nas coberturas das três classes, de até $0,19 \%$.

Pela Tabela 4, verifica-se ainda que a Classe 2 recebe o maior valor de irradiação nas fachadas, seguida da Classe 3 e 1. A tabela também demonstra que nenhuma das classes apresentou potencial de produção energética suficiente para suprir a demanda de energia elétrica. Os edifícios com menor área possuem menor demanda energética e, portanto, maior potencial de suprir a demanda com a produção. Por ter os edifícios mais baixos, a Classe 1 possui o melhor desempenho nesse quesito, seguida pelas Classes 2 e 3 , nessa ordem.

A Tabela 5 apresenta os resultados de iluminância obtidos para as três classes. Os lotes e os edifícios das Classes 1 e 2 estão orientados a nordeste, sudoeste, sudeste e noroeste. Os lotes da Classe 3 são orientados a norte, sul, leste e oeste.

Nota-se pela Tabela 5 que nenhuma das classes atinge o mínimo de iluminância recomendado para todas as orientações de fachada. Nesse sentido, a disponibilidade de iluminação natural é considerada baixa.

Tendo em vista que os cenários avaliados refletem o máximo potencial construtivo da Luos (considerando-se o número máximo de pavimentos), verificou-se que a atual legislação pode promover formas urbanas com pouco aproveitamento do recurso solar disponível, sendo possível sua otimização. Nesse sentido, avaliaramse outros cenários permitidos pela Luos.

\section{Etapa 1.4: definição e modelagem dos cenários}

A seguir, apresentam-se as características dos cenários estudados, considerando variações nos afastamentos laterais, taxa de ocupação e número de pavimentos (Tabelas 6 a 8).

\section{Etapa 3: otimização: análise dos resultados}

A análise dos resultados é dividida de acordo com a classe tipo morfológica de referência.

\section{Classe 1}

Apresentam-se na Tabela 9 os resultados obtidos para os cenários da Classe 1. 
Análise das iluminâncias (Eliminatória)

Verificou-se a partir da Tabela 9 que nenhum dos cenários passa na análise de iluminâncias. Embora as fachadas nordeste e sudoeste apresentem níveis satisfatórios de iluminância, as fachadas sudeste e noroeste não alcançaram o nível mínimo exigido. Essas fachadas são majoritariamente laterais e têm pouca disponibilidade de iluminação natural por estarem muito próximas umas das outras.

Tabela 4 - Irradiância nas coberturas, fachadas e potencial energético das três classes

\begin{tabular}{l|c|c|c}
\hline & Classe 1 & Classe 2 & Classe 3 \\
\hline Irradiância nas coberturas $\left(\mathrm{kWh} / \mathrm{m}^{2}\right.$.ano) & $1.559,49$ & $1.558,18$ & $1.561,22$ \\
Irradiância nas fachadas por $\mathrm{m}^{2}\left(\mathrm{kWh} / \mathrm{m}^{2}\right.$.ano) & 204,17 & 249,80 & 221,24 \\
Produção > Consumo & Não & Não & Não \\
\hline
\end{tabular}

Tabela 5 - Avaliação da iluminância (em lux) para as três classes

\begin{tabular}{c|c|c|c|c|c|c|c|c}
\hline Classe & $\begin{array}{c}\text { Ilum. } \\
\text { média } \\
\text { fachadas } \\
\text { nordeste }\end{array}$ & $\begin{array}{c}\text { Ilum. } \\
\text { média } \\
\text { fachadas } \\
\text { sudoeste }\end{array}$ & $\begin{array}{c}\text { Ilum. } \\
\text { média } \\
\text { fachadas } \\
\text { sudeste }\end{array}$ & $\begin{array}{c}\text { Ilum. } \\
\text { média } \\
\text { fachadas } \\
\text { noroeste }\end{array}$ & $\begin{array}{c}\text { Ilum. } \\
\text { média } \\
\text { fachadas } \\
\text { norte }\end{array}$ & $\begin{array}{c}\text { Ilum. } \\
\text { média } \\
\text { fachadas } \\
\text { sul }\end{array}$ & $\begin{array}{c}\text { Ilum. } \\
\text { média } \\
\text { fachadas } \\
\text { leste }\end{array}$ & $\begin{array}{c}\text { Ilum. } \\
\text { Média } \\
\text { fachadas } \\
\text { oeste }\end{array}$ \\
\hline Alvo & $>=8.233$ & $>=6.733$ & $>=7.166$ & $>=8.966$ & $>=9.833$ & $>=6.800$ & $>=7.600$ & $>=7.466$ \\
1 & 9.419 & 9.532 & 2.437 & 2.166 & - & - & - & - \\
2 & 6.199 & 5.426 & 9.566 & 8.638 & - & - & - & - \\
3 & - & - & - & - & 4.143 & 4.507 & 16.950 & 14.570 \\
\hline
\end{tabular}

Nota: Legenda:

Valor igual ou acima do limite de iluminância; e

Valor abaixo do limite de iluminância.

Tabela 6 - Caracterização dos cenários estudados - classe 1

\begin{tabular}{c|c|c|c|c|c|c|c}
\hline \multirow{2}{*}{ Cenário } & Afastamentos & \multicolumn{2}{|c|}{ Taxa de ocupação (35\% a 100\%) } & \multicolumn{3}{c}{ Número de pavimentos (1 a 4) } \\
\cline { 3 - 7 } 1 & laterais & RO1 (2) & RO2 & CSIIR2 (2) & RO1 (2) & RO2 & CSIIR2 (2) \\
2 & Sim & $35 \%$ & $35 \%$ & $45 \%$ & 1 & 1 & 2 \\
3 & Sim & $35 \%$ & $35 \%$ & $45 \%$ & 2 & 2 & 3 \\
4 & Sim & $35 \%$ & $35 \%$ & $45 \%$ & 3 & 3 & 4 \\
5 & Sim & $50 \%$ & $50 \%$ & $65 \%$ & 1 & 1 & 2 \\
6 & Sim & $50 \%$ & $50 \%$ & $65 \%$ & 2 & 2 & 3 \\
7 & Sim & $50 \%$ & $50 \%$ & $65 \%$ & 3 & 3 & 4 \\
8 & Sim & $65 \%$ & $65 \%$ & $100 \%$ & 1 & 1 & 2 \\
$9 *$ & Sim & $65 \%$ & $65 \%$ & $100 \%$ & 2 & 2 & 3 \\
10 & Sim & $65 \%$ & $65 \%$ & $100 \%$ & 3 & 3 & 4 \\
$11 *$ & Sim & $80 \%$ & $80 \%$ & $100 \%$ & 1 & 1 & 2 \\
12 & Sim & $80 \%$ & $80 \%$ & $100 \%$ & 2 & 2 & 4 \\
13 & Não & $35 \%$ & $35 \%$ & $45 \%$ & 1 & 1 & 2 \\
14 & Não & $35 \%$ & $35 \%$ & $45 \%$ & 2 & 2 & 3 \\
15 & Não & $35 \%$ & $35 \%$ & $45 \%$ & 3 & 3 & 4 \\
16 & Não & $50 \%$ & $50 \%$ & $65 \%$ & 1 & 1 & 2 \\
17 & Não & $50 \%$ & $50 \%$ & $65 \%$ & 2 & 2 & 3 \\
18 & Não & $50 \%$ & $50 \%$ & $65 \%$ & 3 & 3 & 4 \\
19 & Não & $65 \%$ & $65 \%$ & $100 \%$ & 1 & 1 & 2 \\
$20 *$ & Não & $65 \%$ & $65 \%$ & $100 \%$ & 2 & 2 & 3 \\
21 & Não & $65 \%$ & $65 \%$ & $100 \%$ & 3 & 3 & 4 \\
$22 *$ & Não & $80 \%$ & $80 \%$ & $100 \%$ & 1 & 1 & 2 \\
\hline
\end{tabular}

Nota: *cenários com o máximo potencial construtivo. 
Tabela 7 - Caracterização dos cenários a serem estudados - classe 2

\begin{tabular}{|c|c|c|c|c|c|c|c|}
\hline \multirow{2}{*}{ Cenário } & \multirow{2}{*}{$\begin{array}{c}\text { Afastamentos } \\
\text { Laterais }\end{array}$} & \multicolumn{3}{|c|}{ Taxa de ocupação (50\% a $80 \%)$} & \multicolumn{3}{|c|}{ Número de pavimentos (1 a 9) } \\
\hline & & RE3 & CSIIR2 (1) & CSIIR2 (2) & RE3 & CSIIR2 (1) & CSIIR2 (2) \\
\hline 1 & Sim & $50 \%$ & $50 \%$ & $50 \%$ & 4 & 1 & 2 \\
\hline 2 & Sim & $50 \%$ & $50 \%$ & $50 \%$ & 7 & 2 & 3 \\
\hline 3 & Sim & $50 \%$ & $50 \%$ & $50 \%$ & 9 & 3 & 4 \\
\hline 4 & Sim & $65 \%$ & $65 \%$ & $65 \%$ & 4 & 1 & 2 \\
\hline 5 & Sim & $65 \%$ & $65 \%$ & $65 \%$ & 7 & 2 & 3 \\
\hline 6 & Sim & $65 \%$ & $65 \%$ & $65 \%$ & 9 & 3 & 4 \\
\hline 7 & Sim & $80 \%$ & $80 \%$ & $80 \%$ & 4 & 1 & 2 \\
\hline 8 & Sim & $80 \%$ & $80 \%$ & $80 \%$ & 7 & 2 & 3 \\
\hline 9 & Sim & $80 \%$ & $80 \%$ & $80 \%$ & 9 & 3 & 4 \\
\hline 10 & Não & $50 \%$ & $50 \%$ & $50 \%$ & 4 & 1 & 2 \\
\hline 11 & Não & $50 \%$ & $50 \%$ & $50 \%$ & 7 & 2 & 3 \\
\hline 12 & Não & $50 \%$ & $50 \%$ & $50 \%$ & 9 & 3 & 4 \\
\hline 13 & Não & $65 \%$ & $65 \%$ & $65 \%$ & 4 & 1 & 2 \\
\hline 14 & Não & $65 \%$ & $65 \%$ & $65 \%$ & 7 & 2 & 3 \\
\hline 15 & Não & $65 \%$ & $65 \%$ & $65 \%$ & 9 & 3 & 4 \\
\hline 16 & Não & $80 \%$ & $80 \%$ & $80 \%$ & 4 & 1 & 2 \\
\hline 17 & Não & $80 \%$ & $80 \%$ & $80 \%$ & 7 & 2 & 3 \\
\hline 18 & Não & $80 \%$ & $80 \%$ & $80 \%$ & 9 & 3 & 4 \\
\hline 19 & Não & $100 \%$ & $100 \%$ & $100 \%$ & 4 & 1 & 2 \\
\hline 20 & Não & $100 \%$ & $100 \%$ & $100 \%$ & 7 & 2 & 3 \\
\hline $21 *$ & Não & $100 \%$ & $100 \%$ & $100 \%$ & 9 & 3 & 4 \\
\hline
\end{tabular}

Nota: *cenários com o máximo potencial construtivo.

Tabela 8 - Caracterização dos cenários a serem estudados- classe 3

\begin{tabular}{c|c|c|c}
\hline Cenário & $\begin{array}{c}\text { Afastamentos } \\
\text { laterais }\end{array}$ & $\begin{array}{c}\text { Taxa de ocupação } \\
(\mathbf{1 5 \%} \text { a 60\%) }\end{array}$ & $\begin{array}{c}\text { Número de pavimentos } \\
(\mathbf{1} \text { a 20) }\end{array}$ \\
\hline 1 & Centro & $15 \%$ & 1 \\
2 & Centro & $15 \%$ & 5 \\
3 & Centro & $15 \%$ & 10 \\
4 & Centro & $15 \%$ & 15 \\
$5^{*}$ & Centro & $15 \%$ & 20 \\
6 & Centro & $30 \%$ & 1 \\
7 & Centro & $30 \%$ & 5 \\
$8^{*}$ & Centro & $30 \%$ & 10 \\
9 & Centro & $45 \%$ & 1 \\
10 & Centro & $45 \%$ & 5 \\
11 & Centro & $60 \%$ & 1 \\
$12 *$ & Centro & $60 \%$ & 5 \\
13 & Fundo & $15 \%$ & 1 \\
14 & Fundo & $15 \%$ & 5 \\
15 & Fundo & $15 \%$ & 10 \\
16 & Fundo & $15 \%$ & 15 \\
$17 *$ & Fundo & $15 \%$ & 20 \\
18 & Fundo & $30 \%$ & 1 \\
19 & Fundo & $30 \%$ & 5 \\
$20 *$ & Fundo & $30 \%$ & 10 \\
21 & Fundo & $45 \%$ & 1 \\
\hline
\end{tabular}

Nota: *cenários com o máximo potencial construtivo. 
Tabela 9 - Resultados dos cenários da Classe 1

\begin{tabular}{|c|c|c|c|c|c|c|c|}
\hline Cenários & $\begin{array}{l}\text { Irradiância } \\
\text { anual } \\
\text { recebida nas } \\
\text { coberturas } \\
\left(\mathrm{kWh} / \mathrm{m}^{2} \text {.ano) }\right.\end{array}$ & $\begin{array}{c}\text { Irradiância } \\
\text { anual recebida } \\
\text { nas fachadas } \\
\left(\mathbf{k W h} / \mathbf{m}^{2} \text {.ano }\right)\end{array}$ & $\begin{array}{c}\text { Ilum. } \\
\text { anual } \\
\text { fachadas } \\
\text { nordeste } \\
\text { (lux) }\end{array}$ & $\begin{array}{c}\text { Ilum. } \\
\text { anual } \\
\text { fachadas } \\
\text { sudoeste } \\
\text { (lux) }\end{array}$ & $\begin{array}{c}\text { Ilum. } \\
\text { anual } \\
\text { fachadas } \\
\text { sudeste } \\
\text { (lux) }\end{array}$ & $\begin{array}{c}\text { Ilum. } \\
\text { anual } \\
\text { fachadas } \\
\text { noroeste } \\
\text { (lux) }\end{array}$ & $\begin{array}{c}\text { Produção > } \\
\text { Consumo }\end{array}$ \\
\hline 1 & $1.558,40$ & 286,65 & 10.959 & 11.226 & 7.784 & 5.904 & Sim \\
\hline 2 & $1.559,57$ & 287,88 & 11.880 & 10.979 & 7.590 & 5.980 & Sim \\
\hline 3 & $1.558,61$ & 276,21 & 11.862 & 11.164 & 6.799 & 5.624 & Não \\
\hline 4 & $1.559,71$ & 266,99 & 11.286 & 10.661 & 6.579 & 5.094 & Sim \\
\hline 5 & $1.559,39$ & 260,94 & 11.747 & 10.390 & 6.380 & 4.936 & Sim \\
\hline 6 & $1.559,56$ & 243,35 & 10.964 & 10.663 & 5.652 & 4.444 & Não \\
\hline 7 & $1.560,31$ & 211,74 & 10.350 & 10.223 & 3.996 & 3.458 & Sim \\
\hline 8 & $1.559,72$ & 210,17 & 10.675 & 9.846 & 4.176 & 3.651 & Sim \\
\hline 9 & $1.560,15$ & 199,46 & 10.203 & 9.564 & 3.627 & 3.532 & Não \\
\hline 10 & $1.557,79$ & 199,87 & 10.253 & 9.889 & 3.582 & 3.105 & Sim \\
\hline 11 & $1.557,19$ & 191,89 & 10.401 & 10.063 & 3.255 & 2.814 & Sim \\
\hline 12 & $1.560,78$ & 237,90 & 10.044 & 10.330 & 2.791 & 2.505 & Sim \\
\hline 13 & $1.561,04$ & 266,56 & 12.685 & 11.053 & 3.053 & 2.355 & Sim \\
\hline 14 & $1.560,32$ & 270,38 & 11.132 & 11.631 & 3.248 & 2.763 & Não \\
\hline 15 & $1.559,18$ & 186,68 & 10.723 & 10.567 & 1.866 & 1.585 & Sim \\
\hline 16 & $1.560,62$ & 232,50 & 11.857 & 11.071 & 2.485 & 2.182 & Sim \\
\hline 17 & $1.559,16$ & 224,62 & 11.955 & 11.020 & 2.563 & 2.254 & Não \\
\hline 18 & $1.559,17$ & 173,72 & 7.181 & 9.348 & 1.923 & 1.525 & Sim \\
\hline 19 & $1.559,70$ & 198,44 & 10.408 & 9.262 & 2.259 & 2.071 & Sim \\
\hline 20 & $1.559,49$ & 204,17 & 9.419 & 9.532 & 2.437 & 2.166 & Não \\
\hline 21 & $1.559,71$ & 148,11 & 9.169 & 9.897 & 1.481 & 935 & Sim \\
\hline 22 & $1.557,92$ & 163,86 & 11.278 & 9.526 & 1.704 & 1.327 & Sim \\
\hline
\end{tabular}

Nota: Legenda:

Valor igual ou acima do limite de iluminância ou de produção energética igual ou maior que o consumo; e Valor abaixo do limite de iluminância ou de produção energética menor que o consumo.

\section{Análise das irradiâncias (Classificatória)}

Tendo em vista que nenhum cenário passou na etapa 1, a análise das irradiâncias não se aplica.

\section{Análise do potencial energético}

Tendo em vista que nenhum cenário passou na etapa 1, a análise do potencial energético não se aplica.

\section{Conclusão}

De maneira geral, os cenários da Classe 1 têm um bom potencial energético por possuir edifícios baixos (de um a quatro pavimentos, com menos área) e por receber altos níveis de irradiância nas coberturas, o que possibilitaria o uso dos painéis fotovoltaicos. Entretanto, eles possuem pouca disponibilidade de iluminação natural, uma vez que nenhum de seus cenários obteve iluminância acima dos limites mínimos estabelecidos como satisfatórios. Sendo assim, nenhum de seus cenários passaria no processo da otimização.

\section{Classe 2}

Apresentam-se na Tabela 10 os resultados obtidos para os cenários da Classe 2.

\section{Análise das iluminâncias (Eliminatória)}

Verificou-se a partir da Tabela 10 que $62 \%$ dos cenários passam nessa etapa. Foram eliminados os cenários que não alcançaram os limites da iluminância, ou seja, aqueles com as maiores taxas de ocupação e os cenários com taxas de ocupação intermediárias e com os maiores números de pavimentos, ou seja, os cenários $6,7,8,9,15,18,19,20$ e 21 . 
Tabela 10 - Resultados dos cenários da Classe 2

\begin{tabular}{|c|c|c|c|c|c|c|c|}
\hline Cenários & $\begin{array}{c}\text { Irradiância } \\
\text { anual recebida } \\
\text { nas coberturas } \\
\left(\mathbf{k W h} / \mathbf{m}^{2} \text {.ano }\right)\end{array}$ & $\begin{array}{c}\text { Irradiância } \\
\text { anual recebida } \\
\text { nas fachadas } \\
\left(\mathrm{kWh} / \mathbf{m}^{2} \text {.ano) }\right.\end{array}$ & $\begin{array}{c}\text { Ilum. } \\
\text { anual } \\
\text { fachadas } \\
\text { nordeste } \\
\text { (lux) }\end{array}$ & $\begin{array}{c}\text { Ilum. } \\
\text { anual } \\
\text { fachadas } \\
\text { sudoeste } \\
\text { (lux) }\end{array}$ & $\begin{array}{c}\text { Ilum. } \\
\text { anual } \\
\text { fachadas } \\
\text { sudeste } \\
\text { (lux) }\end{array}$ & $\begin{array}{c}\text { Ilum. } \\
\text { anual } \\
\text { fachadas } \\
\text { noroeste } \\
\text { (lux) }\end{array}$ & $\begin{array}{c}\text { Produção > } \\
\text { Consumo }\end{array}$ \\
\hline 1 & $1.560,45$ & 340,04 & 9.805 & 9.563 & 11.544 & 10.349 & Sim \\
\hline 2 & $1.560,56$ & 333,34 & 9.894 & 8.532 & 11.678 & 10.634 & Não \\
\hline 3 & $1.558,77$ & 315,67 & 9.037 & 7.724 & 11.132 & 10.362 & Não \\
\hline 4 & $1.561,13$ & 322,15 & 8.930 & 8.483 & 10.229 & 11.112 & Sim \\
\hline 5 & $1.561,05$ & 317,98 & 9.179 & 7.584 & 10.986 & 11.167 & Não \\
\hline 6 & $1.560,28$ & 300,65 & 8.460 & 6.704 & 10.564 & 10.851 & Não \\
\hline 7 & $1.559,10$ & 277,82 & 6.319 & 8.075 & 9.992 & 9.575 & Sim \\
\hline 8 & $1.558,89$ & 285,30 & 7.509 & 7.022 & 10.699 & 10.159 & Não \\
\hline 9 & $1.558,07$ & 269,87 & 6.341 & 6.500 & 10.171 & 10.083 & Não \\
\hline 10 & $1.560,60$ & 334,97 & 14.779 & 7.916 & 12.213 & 11.079 & Sim \\
\hline 11 & $1.560,03$ & 339,48 & 9.929 & 7.448 & 12.143 & 11.597 & Não \\
\hline 12 & $1.559,65$ & 326,60 & 9.047 & 6.899 & 11.752 & 11.474 & Não \\
\hline 13 & $1.560,00$ & 303,50 & 8.790 & 7.814 & 11.278 & 10.302 & Sim \\
\hline 14 & $1.559,46$ & 313,28 & 9.167 & 7.256 & 11.735 & 11.250 & Não \\
\hline 15 & $1.558,72$ & 297,36 & 8.433 & 6.624 & 11.427 & 10.950 & Não \\
\hline 16 & $1.558,07$ & 295,80 & 9.357 & 7.598 & 8.586 & 9.587 & Sim \\
\hline 17 & $1.558,37$ & 304,20 & 9.342 & 6.866 & 9.612 & 10.293 & Não \\
\hline 18 & $1.557,14$ & 283,97 & 8.293 & 6.151 & 9.149 & 10.155 & Não \\
\hline 19 & $1.560,24$ & 273,03 & 7.151 & 6.840 & 10.200 & 8.573 & Sim \\
\hline 20 & $1.559,71$ & 270,60 & 7.261 & 6.029 & 9.913 & 9.072 & Não \\
\hline 21 & $1.558,18$ & 249,80 & 6.199 & 5.426 & 9.566 & 8.638 & Não \\
\hline
\end{tabular}

\section{Análise das irradiâncias (Classificatória)}

Entre os cenários que passaram na análise de iluminância, classificaram-se os que possuem melhor desempenho na análise das irradiâncias, ou seja, aqueles que receberam menores irradiâncias nas fachadas e maiores irradiâncias nas coberturas, conforme a Tabela 11.

De maneira geral, os cenários contendo edifícios com maior taxa de ocupação e menor número de pavimentos têm melhor classificação, haja vista que tais cenários conseguem atingir o mínimo de iluminância exigido e recebem menos irradiância nas fachadas.

\section{Análise do potencial energético}

Entre os cenários que passaram na análise da irradiância, aqueles com os edifícios com menor número de pavimentos possuem maior potencial energético. Isso acontece porque a área desses edifícios é menor, diminuindo-se a demanda energética. Apresentam-se na Tabela 12 os resultados mais bem classificados que passam na análise do potencial energético.

\section{Conclusão}

De maneira geral, os cenários da Classe 2 apresentaram adequada disponibilidade de iluminação natural. Entretanto, tem-se potencial energético para suprir a demanda apenas nos cenários que contêm edifícios com as menores alturas (um a quatro pavimentos). Os cenários com edifícios de altura intermediária não são capazes de suprir a demanda energética com a produção energética.

A análise resultou em dois cenários otimizados: 16 e 13, em ordem decrescente de desempenho. Esses cenários contêm edifícios de um a quatro pavimentos, tendo o primeiro colocado $80 \%$ de taxa de ocupação, e o segundo, $65 \%$. Para a otimização, deve-se limitar o número de pavimentos dos usos CSIIR2 (1), CSIIR2 (2) e RE3 a 1, 2 e 4, se for considerada uma taxa de ocupação de $65 \%$ ou de $80 \%$. 
Tabela 11 - Classificação dos cenários da Classe 2 que passaram na etapa 1

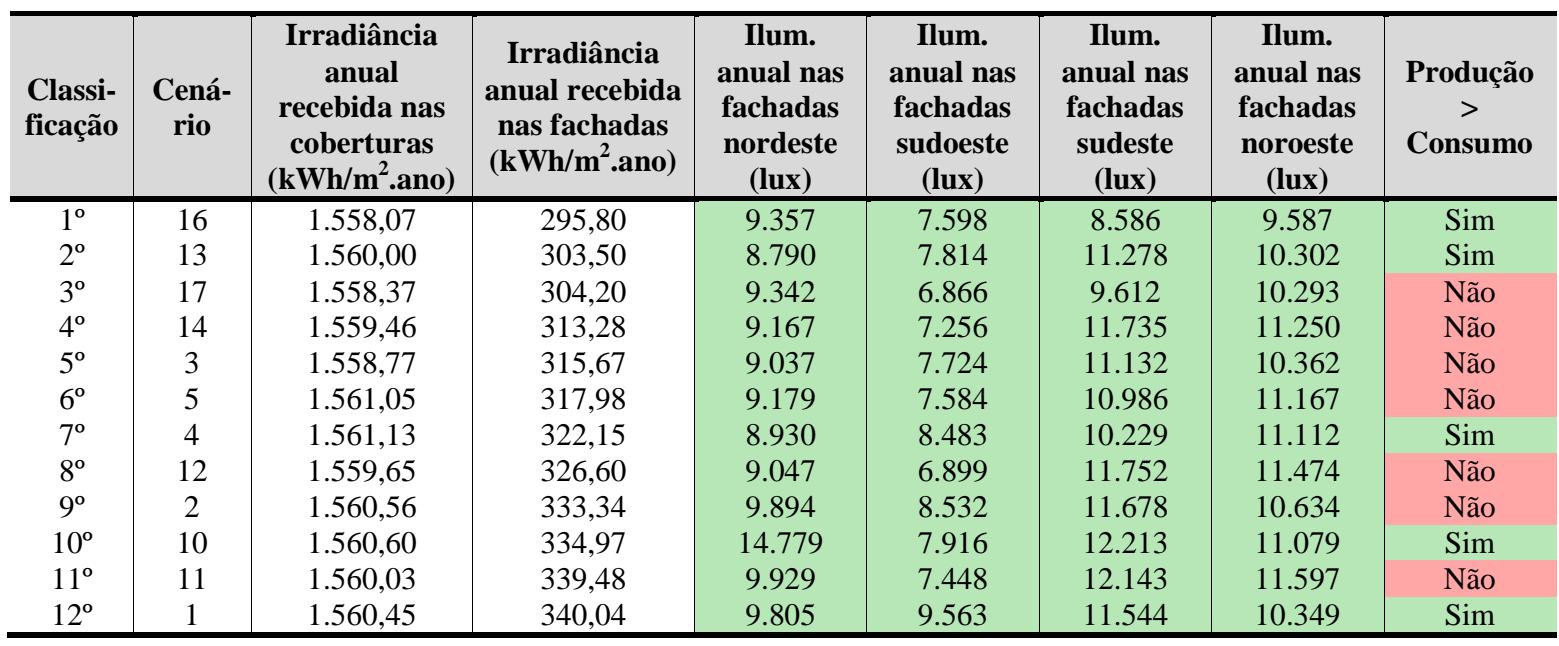

Tabela 12 - Classificação dos cenários da Classe 2 otimizados

\begin{tabular}{|c|c|c|c|c|c|c|c|c|}
\hline $\begin{array}{c}\text { Classifi- } \\
\text { cação }\end{array}$ & $\begin{array}{c}\text { Cená- } \\
\text { rio }\end{array}$ & $\begin{array}{c}\text { Irradiância } \\
\text { anual recebida } \\
\text { nas coberturas } \\
\left(\mathrm{kWh} / \mathrm{m}^{2} \text {.ano) }\right.\end{array}$ & $\begin{array}{c}\text { Irradiância } \\
\text { anual recebida } \\
\text { nas fachadas } \\
\left(\mathrm{kWh} / \mathrm{m}^{2} \text {.ano) }\right.\end{array}$ & $\begin{array}{c}\text { Ilum. } \\
\text { anual } \\
\text { fachadas } \\
\text { nordeste } \\
\text { (lux) }\end{array}$ & $\begin{array}{c}\text { Ilum. } \\
\text { anual } \\
\text { fachadas } \\
\text { sudoeste } \\
\text { (lux) }\end{array}$ & $\begin{array}{c}\text { Ilum. } \\
\text { anual } \\
\text { fachadas } \\
\text { sudeste } \\
\text { (lux) }\end{array}$ & $\begin{array}{c}\text { Ilum. } \\
\text { anual } \\
\text { fachadas } \\
\text { noroeste } \\
\text { (lux) }\end{array}$ & $\begin{array}{c}\text { Produção } \\
> \\
\text { Consumo }\end{array}$ \\
\hline $1^{\circ}$ & 16 & $1.558,07$ & 295,80 & 9.357 & 7.598 & 8.586 & 9.587 & Sim \\
\hline $2^{o}$ & 13 & $1.560,00$ & 303,50 & 8.790 & 7.814 & 11.278 & 10.302 & Sim \\
\hline
\end{tabular}

\section{Classe 3}

Apresentam-se na Tabela 13 os resultados obtidos para os cenários da Classe 3.

\section{Análise das iluminâncias (Eliminatória)}

Verifica-se a partir da Tabela 13 que 20\% dos cenários passam na análise de iluminâncias. São eliminados todos os cenários com mais de um pavimento.

\section{Análise das irradiâncias (Classificatória)}

Entre os cenários que passaram na análise de iluminância, classificam-se os que possuem melhor desempenho na análise das irradiâncias, conforme demonstra a Tabela 14.

Apenas cenários que contêm edifícios de um pavimento e com taxas de ocupação que variam de $15 \%$ a $45 \%$ passam nessa etapa.

\section{Análise do potencial energético}

Todos os cenários que passaram na análise da irradiância possuem alto potencial energético e, por isso, são considerados cenários otimizados.

\section{Conclusão}

Os cenários da Classe 3, em geral, têm pouca disponibilidade de iluminação natural e possuem potencial energético para suprir a demanda apenas nos cenários contendo edifícios com um pavimento. A análise resulta em cinco cenários otimizados: 1, 18, 9, 6 e 13, em ordem decrescente de desempenho. Todos os cenários otimizados contêm edifícios de um pavimento e taxas de ocupação que variam de $15 \%$ a $45 \%$. Os cenários com os edifícios localizados no centro são mais bem classificados. Para a otimização, deve-se limitar o número de pavimentos do uso CSIIR2-Leste Industrial a apenas 1 (a Luos permite até vinte pavimentos) e a taxa de ocupação a $45 \%$ (a Luos permite até $60 \%$ ). 
Tabela 13 - Resultados dos cenários da Classe 3

\begin{tabular}{|c|c|c|c|c|c|c|c|}
\hline Cenários & $\begin{array}{c}\text { Irradiância } \\
\text { anual recebida } \\
\text { nas coberturas } \\
\left(\mathbf{k W h} / \mathbf{m}^{2} \text {.ano }\right)\end{array}$ & $\begin{array}{c}\text { Irradiância } \\
\text { anual recebida } \\
\text { nas fachadas } \\
\left(\mathbf{k W h} / \mathrm{m}^{2} \text {.ano }\right)\end{array}$ & $\begin{array}{c}\text { Ilum. } \\
\text { anual } \\
\text { fachadas } \\
\text { noste } \\
\text { (lux) }\end{array}$ & $\begin{array}{c}\text { Ilum. } \\
\text { anual } \\
\text { fachadas } \\
\text { sul } \\
\text { (lux) }\end{array}$ & $\begin{array}{c}\text { Ilum. } \\
\text { anual } \\
\text { fachadas } \\
\text { leste (lux) }\end{array}$ & $\begin{array}{c}\text { Ilum. } \\
\text { anual } \\
\text { fachadas } \\
\text { oeste } \\
\text { (lux) }\end{array}$ & $\begin{array}{c}\text { Produção > } \\
\text { Consumo }\end{array}$ \\
\hline$\overline{1}$ & $1.560,31$ & 304,89 & 10.125 & 7.547 & 15.767 & 13.033 & Sim \\
\hline 2 & $1.561,11$ & 277,21 & 6.428 & 5.742 & 18.709 & 15.836 & Não \\
\hline 3 & $1.560,86$ & 244,31 & 4.816 & 5.218 & 18.122 & 15.444 & Não \\
\hline 4 & $1.561,29$ & 233,03 & 4.299 & 5.004 & 17.503 & 15.136 & Não \\
\hline 5 & $1.561,22$ & 221,24 & 4.143 & 4.507 & 16.950 & 14.570 & Não \\
\hline 6 & $1.560,42$ & 341,84 & 11.317 & 7.677 & 15.533 & 12.356 & Sim \\
\hline 7 & $1.560,58$ & 279,09 & 7.643 & 5.483 & 17.949 & 14.641 & Não \\
\hline 8 & $1.560,82$ & 239,04 & 5.748 & 4.492 & 17.251 & 14.047 & Não \\
\hline 9 & $1.560,39$ & 325,42 & 10.606 & 7.370 & 14.655 & 12.409 & Sim \\
\hline 10 & $1.560,71$ & 245,17 & 6.174 & 4.545 & 16.412 & 14.258 & Não \\
\hline 11 & $1.560,29$ & 295,46 & 8.443 & 6.896 & 15.794 & 12.271 & Sim \\
\hline 12 & $1.560,79$ & 205,73 & 3.860 & 3.931 & 16.531 & 13.434 & Não \\
\hline 13 & $1.559,68$ & 365,75 & 11.448 & 9.525 & 15.530 & 11.986 & Sim \\
\hline 14 & $1.560,20$ & 312,50 & 9.014 & 7.375 & 16.636 & 13.688 & Não \\
\hline 15 & $1.560,58$ & 269,06 & 6.979 & 6.364 & 15.754 & 13.080 & Não \\
\hline 16 & $1.560,25$ & 255,43 & 6.389 & 6.002 & 15.217 & 12.826 & Não \\
\hline 17 & $1.560,95$ & 241,26 & 6.065 & 5.428 & 14.792 & 12.323 & Não \\
\hline 18 & $1.560,80$ & 316,85 & 10.138 & 7.385 & 14.772 & 11.596 & Sim \\
\hline 19 & $1.560,95$ & 249,77 & 5.996 & 4.633 & 15.586 & 11.540 & Não \\
\hline 20 & $1.560,69$ & 205,23 & 4.808 & 4.001 & 14.464 & 11.813 & Não \\
\hline 21 & $1.560,22$ & 311,72 & 10.687 & 6.766 & 14.159 & 11.110 & Sim \\
\hline 22 & $1.560,81$ & 225,20 & 6.199 & 4.234 & 14.629 & 11.508 & Não \\
\hline 23 & $1.560,91$ & 287,63 & 9.062 & 6.054 & 15.099 & 11.676 & Sim \\
\hline 24 & $1.560,66$ & 195,62 & 4.264 & 3.427 & 15.177 & 12.192 & Não \\
\hline
\end{tabular}

Tabela 14 - Classificação dos cenários da Classe 3 que passaram na etapa 1

\begin{tabular}{|c|c|c|c|c|c|c|c|c|}
\hline $\begin{array}{c}\text { Classifi- } \\
\text { cação }\end{array}$ & $\begin{array}{l}\text { Cená- } \\
\text { rio }\end{array}$ & $\begin{array}{c}\text { Irradiância } \\
\text { anual } \\
\text { recebida nas } \\
\text { coberturas } \\
\left(\mathrm{kWh} / \mathrm{m}^{2} \text {.ano }\right)\end{array}$ & $\begin{array}{c}\text { Irradiância } \\
\text { anual recebida } \\
\text { nas fachadas } \\
\left(\mathbf{k W h} / \mathbf{m}^{2} \text {.ano }\right)\end{array}$ & $\begin{array}{c}\text { Ilum. } \\
\text { anual } \\
\text { fachadas } \\
\text { norte } \\
\text { (lux) }\end{array}$ & $\begin{array}{c}\text { Ilum. } \\
\text { anual } \\
\text { fachadas } \\
\text { sul } \\
\text { (lux) }\end{array}$ & $\begin{array}{c}\text { Ilum. } \\
\text { anual } \\
\text { fachadas } \\
\text { leste } \\
\text { (lux) }\end{array}$ & $\begin{array}{c}\text { Ilum. } \\
\text { anual } \\
\text { fachadas } \\
\text { oeste } \\
\text { (lux) }\end{array}$ & $\begin{array}{c}\text { Produção } \\
> \\
\text { Consumo }\end{array}$ \\
\hline $1^{\circ}$ & 1 & $1.560,31$ & 304,89 & 10.125 & 7.547 & 15.767 & 13.033 & Sim \\
\hline $2^{\circ}$ & 18 & $1.560,80$ & 316,85 & 10.138 & 7.385 & 14.772 & 11.596 & Sim \\
\hline $3^{\circ}$ & 9 & $1.560,39$ & 325,42 & 10.606 & 7.370 & 14.655 & 12.409 & Sim \\
\hline $4^{\circ}$ & 6 & $1.560,42$ & 341,84 & 11.317 & 7.677 & 15.533 & 12.356 & Sim \\
\hline $5^{\circ}$ & 13 & $1.559,68$ & 365,75 & 11.448 & 9.525 & 15.530 & 11.986 & Sim \\
\hline
\end{tabular}

De maneira geral, comparativamente a trabalhos anteriores na mesma linha, Martins, Adolphe e Bastos (2014) realizaram a otimização dos resultados através do programa modeFRONTIER, o que possibilitou maior quantidade de parâmetros avaliados, garantindo-se maior diversidade de formas urbanas estudadas. Tanto naquele quanto neste trabalho, no entanto, nota-se a dificuldade da otimização das formas urbanas com edificações contíguas, pela dificuldade de se atingirem os níveis mínimos de iluminância nas fachadas. Os resultados otimizados são específicos para os contextos de avaliação estabelecidos nos estudos, com relação a clima e localização, não sendo aplicáveis a contextos diferentes. O método utilizado nos estudos, entretanto, pode ser replicado, sendo o de Martins, Adolphe e Bastos (2014) mais completo, e o do presente artigo, simplificado. Ambos demonstram que, além da adequação dos limites dos parâmetros de ocupação (taxa de ocupação e número de pavimentos), é importante que o desenho dos lotes (tamanho, afastamentos e orientação) também contribua para o aproveitamento da energia solar. 


\section{Conclusão}

Com relação ao estudo de caso específico, a fim de garantir o adequado aproveitamento da energia solar, de acordo com as estratégias propostas, considera-se que devem ser revistos os limites dos parâmetros de ocupação determinados pela Luos, conforme apresentado nos resultados. Pode-se concluir que os cenários com menos pavimentos promovem melhor aproveitamento da energia solar. Entre esses cenários, se os lotes são predominantemente mais próximos uns dos outros, uma taxa de ocupação menor promove melhor desempenho, enquanto nos lotes mais afastados uns dos outros uma taxa de ocupação maior promove melhor desempenho. No entanto, quando os lotes são pequenos e próximos, mesmo uma taxa de ocupação menor não é capaz de promover um nível de iluminância satisfatório nas fachadas. Os resultados evidenciam dificuldade em atingir níveis satisfatórios de iluminância nas fachadas em lotes pequenos, próximos e com alta taxa de ocupação, uma vez que foram obtidas somente sete formas urbanas otimizadas.De maneira geral, conclui-se sobre a relevância do desenho dos lotes (tamanho, afastamentos, orientação) e sua integração com os parâmetros de ocupação (taxa de ocupação e número de pavimentos) para a otimização do uso da energia solar e iluminação natural.

O presente artigo propõe uma simplificação do método de Martins, Adolphe e Bastos (2014) e comprova sua viabilidade através da obtenção de resultados consistentes e coerentes com o trabalho citado, podendo ser ulteriormente aplicado a outras condições climáticas e urbanas, a fim de otimizar o desenho urbano quanto a sua influência no potencial de produção energética, condições de iluminação natural interna e controle de radiação nas fachadas dos edifícios.

\section{Referências}

COLOMBERT, M. Contribution à l'analyse de la prise en compte du climat urbain dans les différents moyens d'intervention sur la ville. Paris, 2008. 538 f. Tese (Doutorado em Engenharia Urbana) Université Paris, Paris, 2008.

COSTA, J.; OLIVEIRA, N.; AMORIM, C. Morphological characteristics and energy consumption of office buildings in the central area of Brasilia. In: PASSIVE LOW ENERGY ARCHITECTURE, 33., Edinburgh, 2017. Proceedings [...] Edinburgh: PLEA, 2017.

CRONEMBERGER, J. Integración de sistemas fotovoltaicos en edificios de oficinas en bajas latitudes: estudio del balance energético aplicado a Brasil. Madrid, 2015. 56 f. Tese - Escuela Técnica Superior de Arquitectura, Universidad Politécnica de Madrid, Madrid, 2015.

DIRETORIA DE ESTUDOS URBANOS E AMBIENTAIS; COMPANHIA DE PLANEJAMENTO DO DISTRITO FEDERAL. Estudo urbano ambiental do Gama. Disponível em: http://www.codeplan.df.gov.br/images/CODEPLAN/PDF/pesquisa_socioeconomica/DEURA/Estudo_Urban o_Ambiental-Gama_2015.pdf. Acesso em: 25 abr. 2016.

DISTRITO FEDERAL. Lei Complementar $n^{\circ}$ 948, de 16 de janeiro de 2019. Diário Oficial do Distrito Federal, Brasília, 16 jan. 2019.

DOMINGOS, L. et al. Definição de uma classificação climática para o estudo de edificações com balanço anual zero de energia no Brasil. In: ENCONTRO NACIONAL DE TECNOLOGIA DO AMBIENTE CONSTRUÍDO, 15., Maceió, 2014. Anais [...] Maceió: Antac, 2014.

FEDRIGO, N. S.; GHISI, E.; LAMBERTS, R. Usos finais de energia elétrica no setor residencial brasileiro. In: ENCONTRO NACIONAL DE CONFORTO NO AMBIENTE CONSTRUÍDO, 10., Natal, 2009. Anais [...] Natal: ANTAC, 2009.

FREITAS, T. A expansão urbana no Distrito Federal e a dinâmica do mercado imobiliário: o caso do Gama. Brasília, 2013. 135 f. Dissertação (Mestrado em Geografia) - Departamento de Geografia, Universidade de Brasília, Brasília, 2013.

GROSSO, M. Urban form and renewable energy potential. Renewable Energy, v. 15, n. 1/4, p. 331-336, 1998.

INSTITUTO BRASILEIRO DE GEOGRAFIA E ESTATÍSTICA. Projeção da população do Brasil e das unidades da federação. Disponível em: http://www.ibge.gov.br/apps/populacao/projecao/. Acesso em: 17 abr. 2016. 
KANTERS, J.; HORVAT, M. Solar energy as a design parameter in urban planning. Energy Procedia, v. 30, p. 1143-1152, 2012.

LABORATÓRIO DE EFICIÊNCIA ENERGÉTICA EM EDIFICAÇÕES. Arquivos climáticos INMET 2012. Disponível em: http://www.labeee.ufsc.br/downloads/arquivos-climaticos/formato-epw. Acesso em: 25 dez. 2016.

LAMBERTS, R.; DUTRA, L.; PEREIRA, F. Eficiência energética na arquitetura. 3. ed. Rio de Janeiro: Eletrobras; Procel, 2014.

LITTLEFAIR, P. Daylight, sunlight and solar gain in the urban environment. Solar Energy, London, v. 70, n. 3, p. 177-185, 2001.

MARTINS, T.; ADOLPHE, L.; BASTOS, L. From solar constraints to urban design opportunities: optimization of built form typologies in a Brazilian tropical city. Energy and Buildings, v. 76, p. 43-56, 2014.

MINISTÉRIO DE MINAS E ENERGIA; EMPRESA DE PESQUISA ENERGÉTICA. Inserção da geração fotovoltaica distribuída no Brasil: condicionantes e impactos. Rio de Janeiro, 2014.

MINISTÉRIO DE MINAS E ENERGIA; EMPRESA DE PESQUISA ENERGÉTICA. Balanço energético nacional. Disponível em: http://www.epe.gov.br/sites-pt/publicacoes-dados-

abertos/publicacoes/PublicacoesArquivos/publicacao-377/topico470/Relat\%C3\%B3rio\%20S\%C3\%ADntese\%20BEN\%202019\%20Ano\%20Base\%202018.pdf. Acesso em: 23 jul. 2019.

MONTAVON, M. Optimisation of urban form by the evaluation of the solar potential. Lausanne, $255 \mathrm{f}$. Tese - Faculté Environnement Naturel, Architectural et Construit, École Polytechnique Fédérale de Lausanne, Lausanne, 2010.

MORAES, L.; PEREIRA, F. Um método simplificado para avaliação do desempenho dinâmico da iluminação natural. In: ENCONTRO NACIONAL DE CONFORTO NO AMBIENTE CONSRUÍDO, 7.; ENCONTRO LATINO AMERICANO DE CONFORTO NO AMBIENTE CONSTRUÍDO, 11., Búzios, 2011. Anais [...] Búzios, 2011.

NABIL, A.; MARDALJEVIC, J. Useful daylight illuminances: a replacement for daylight factors. Energy and Buildings, v. 38, n. 7, p. 905-913, 2006.

RATTI, C.; BAKER, N.; STEEMERS, K. Energy consumption and urban texture. Energy and Buildings, v. 37, n. 7, p. 762-776, 2005.

SALAT, S. Cities and forms: on sustainable urbanism. Paris: Hermann, 2011.

SALOMON, V.; SHIMIZU, T. Performance of three different methods of multiple criteria decision making applied to the supplier selection. In: INTERNATIONAL CONFERENCE ON MULTIPLE CRITERIA DECISION MAKING, 18., Greece, 2006. Proceedings [...] Greece, 2006.

SCARAZZATO, P. O conceito de dia típico de projeto aplicado à iluminação natural: dados referenciais para localidades brasileiras. São Paulo, 1995. Tese (Doutorado em Arquitetura e Urbanismo) - Faculdade de Arquitetura e Urbanismo, Universidade de São Paulo, São Paulo, 1995.

SECRETARIA DE ESTADO DE GESTÃO DO TERRITÓRIO E HABITAÇÃO. LUOS: mapa de zoneamento de usos do Gama. Disponível em: http://www.segeth.df.gov.br/preservacao-e-planejamentourbano/lei-complementar-deuso-e-ocupacao-do-solo-do-df.html. Acesso em: 4 out. 2016a.

SECRETARIA DE ESTADO DE GESTÃO DO TERRITÓRIO E HABITAÇÃO. LUOS: tabela de parâmetros de ocupação do solo da região administrativa do Gama. Disponível em:

http://www.segeth.df.gov.br/preservacao-eplanejamento-urbano/lei-complementar-de-uso-e-ocupacao-dosolo-do-df.html. Acesso em: 4 out. 2016b.

TREGENZA, P.; LOE, D. Projeto de iluminação. Porto Alegre: Bookman, 2015.

TURKIENICZ, B.; GONÇALVES, B.; GRAZZIOTIN, P. CityZoom: a visualization tool for the assessment of planning regulations. International Journal of Architecture Computing, v. 6, n. 1, p. 79-95, 2008.

608 Birck, M. B.; Amorim, C. N. D. 


\section{Agradecimentos}

Este trabalho foi realizado com apoio do Conselho Nacional de Desenvolvimento Científico e Tecnológico.

\section{Márcia Bocacio Birck}

Programa de Pós-Graduação em Arquitetura e Urbanismo | Universidade de Brasília | Campus Universitário Darcy Ribeiro, Ala Norte - Asa Norte | Brasília - DF - Brasil | CEP 70910-900 | Tel.: (61) 3107-7444 | E-mail: birck.marcia@gmail.com

Cláudia Naves David Amorim

Programa de Pós-Graduação em Arquitetura e Urbanismo | Universidade de Brasília | E-mail: clamorim@unb.br

\section{Ambiente Construído}

Revista da Associação Nacional de Tecnologia do Ambiente Construído

Av. Osvaldo Aranha, $99-3^{\circ}$ andar, Centro

Porto Alegre - RS - Brasil

CEP $90035-190$

Telefone: +55 (51) 3308-4084

Fax: +55 (51) 3308-4054

www.seer.ufrgs.br/ambienteconstruido

E-mail: ambienteconstruido@ufrgs.br 